\begin{tabular}{|c|c|}
\hline Title & A ctivation cross sections of al pha particle induced nuclear reactions on natural palladium \\
\hline Author(s) & A ikawa, M; Saito, M; Komori, Y; Haba, H; Takács, S; Ditrói, F; Sz cs, Z \\
\hline Citation & $\begin{array}{l}\text { Nuclear Instruments and Methods in Physics Research Section B : Beam Interactions with Materials and A toms, } 449 \text {, } \\
99-104 \\
\text { https://doi.org/10.1016/.nimb.2019.04.066 }\end{array}$ \\
\hline Issue Date & $2019-06-15$ \\
\hline Doc URL & http:/hdl.handle.net/2115/81100 \\
\hline Rights & $\begin{array}{l}\text { (C2019. This manuscript version is made available under the CC-BY-NC-ND } 4.0 \text { license } \\
\text { http://creativecommons.org/icenses/by-nc-nd/4.0/ }\end{array}$ \\
\hline Rights(URL) & http://creativecommons.org/icenses/by-nc-nd/4.0/ \\
\hline Type & article (author version) \\
\hline File Information & NUCL INSTRUM METH B449_99-104.pdf \\
\hline
\end{tabular}

Instructions for use 


\title{
Activation cross sections of alpha-particle induced nuclear reactions on natural palladium
}

\author{
M. Aikawaa,, M. Saito ${ }^{b, 1}$, Y. Komoric, H. Habac, S. Takács ${ }^{d}$, F. Ditróid ${ }^{d}$ Z. Szúcs ${ }^{d}$ \\ a Faculty of Science, Hokkaido University, Sapporo 060-0810, Japan \\ b Graduate School of Science, Hokkaido University, Sapporo 060-0810, Japan \\ c Nishina Center for Accelerator-Based Science, RIKEN, Wako 351-0198, Japan \\ d Institute for Nuclear Research, Hungarian Academy of Sciences (ATOMKI), 4026 \\ Debrecen, Hungary
}

\section{Keyword}

Excitation function; Cross section; Alpha-particle irradiation; Palladium target

\begin{abstract}
The activation cross sections of the alpha-particle induced reactions on natural palladium were determined up to $50 \mathrm{MeV}$ using the stacked-foil technique and highresolution gamma-ray spectrometry. Production cross sections of $111 \mathrm{~m}, 109,107,105,104 \mathrm{Cd}$ and $111 \mathrm{~g}, 110 \mathrm{~m}, 106 \mathrm{~m}, 105 \mathrm{~g}, 103 \mathrm{~g} A \mathrm{~g}$ were obtained. The results were compared with the data of previous experiments and results of theoretical model calculations.
\end{abstract}

\section{Introduction}

Production cross sections of medical radioactive isotopes (RI) are fundamental information for applications such as therapy and diagnostics [1,2]. The knowledge on the cross sections is required to optimize the production of a radioisotope and to produce the appropriate amount of RI. One of such medical RI is the ${ }^{103} \mathrm{Pd}\left(\mathrm{T}_{1 / 2}=16.991 \mathrm{~d}\right)$, which is used for brachytherapy [3,4] and targeted radionuclide therapy as part of the ${ }^{103} \mathrm{Pd} / 103 \mathrm{~m} \mathrm{Rh}$ in vivo generator [5]. In addition to the direct production of ${ }^{103} \mathrm{Pd}$, it is worth to investigate the production of its parent, ${ }^{103} \mathrm{Ag}$. The ${ }^{103} \mathrm{Ag}$ has an isomeric state ${ }^{103 \mathrm{~m}} \mathrm{Ag}$ at $134.4 \mathrm{keV}$ excitation energy $\left(\mathrm{T}_{1 / 2}=5.7 \mathrm{~s}\right)$, which cumulatively contributes to the production of the ground state ${ }^{103 \mathrm{~g} A g}\left(\mathrm{~T}_{1 / 2}=65.7 \mathrm{~min}\right)$.

\footnotetext{
* Corresponding author: aikawa@sci.sci.hokudai.ac.jp

1 Present address: Graduate School of Biomedical Science and Engineering, Hokkaido University, Sapporo 060-8638, Japan
} 
Several charged-particle induced reactions on natPd can be considered for the ${ }^{103} \mathrm{Ag}$ production. According to the survey in the EXFOR library [6], proton- [4,7-9], deuteron$[4,10,11],{ }^{3} \mathrm{He}^{-}[12]$ and alpha-induced reactions [13] on natPd already have been studied. In the case of alpha-particle induced reactions on nat $\mathrm{Pd}$, only one experimental dataset is available below $37 \mathrm{MeV}$ [13]. Therefore, we are motivated to perform an experiment to

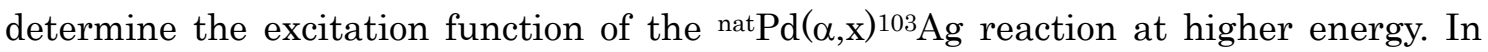
addition to the ${ }^{103 \mathrm{~g}} \mathrm{Ag}$ production, we also deduced activation cross sections of several $\mathrm{Cd}$

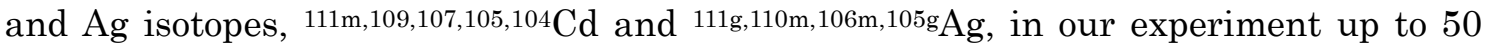
$\mathrm{MeV}$. 


\section{Experimental}

The experiment was performed at the RIKEN AVF cyclotron by using the standard stacked-foil technique and the activation method with high-resolution gamma-ray spectrometry. Thin palladium foils (purity 99.95\%, Nilaco Corp., Japan) with natural isotopic composition (102 $\mathrm{Pd} 1.02 \%,{ }^{104} \mathrm{Pd} 11.14 \%,{ }^{105} \mathrm{Pd} 22.33 \%,{ }^{106} \mathrm{Pd} 27.33 \%,{ }^{108} \mathrm{Pd}$ $26.46 \%,{ }^{110} \mathrm{Pd} 11.72 \%$ ) were used with natTi monitor foils (purity 99.9\%, Goodfellow Co., Ltd., UK). The foils were cut from a larger sheet, of which size and weight were measured. Average thicknesses of the Pd and Ti foils were found to be $9.70 \mathrm{mg} / \mathrm{cm}^{2}$ and $4.85 \mathrm{mg} / \mathrm{cm}^{2}$, respectively. The stacked target consisted of 12 sets of the group of Pd-Pd-Ti-Ti foils. Foils were doubled to compensate the recoil effect in every second foil at the downstream of the beam. The stacked foil target was irradiated for 2 hours by the $51.2 \pm 0.1 \mathrm{MeV}$ alpha-particle beam with an average intensity of $111.4 \mathrm{nA}$, which was measured by a Faraday cup. The initial beam energy was determined by the time-of-flight method using a plastic scintillator monitor [14]. The energy degradation of the beam in the stack was calculated using the polynomial approximation of the stopping power data [15]. The $\gamma^{-}$ spectra of the irradiated foils were measured by HPGe detectors (ORTEC GEM-25185-P and ORTEC GEM35P4-70) and analyzed by Gamma Studio (SEIKO EG\&G). To follow the decay of the reaction products with half-lives between $50 \mathrm{~min}$. and 460 days spectra were measured four times. The cooling times of the measurements are $45 \mathrm{~min}, 3.6$ hours, 2.3 and 244 days, respectively. Nuclear decay data were taken from the online NuDat 2.7 database [16] and Q-value calculator [17] (Table 1).

Table 1

Reaction and decay data of the investigated reaction products. Only the gammalines used in the analysis are listed

\begin{tabular}{|c|c|c|c|c|c|c|}
\hline $\begin{array}{l}\text { Reaction } \\
\text { product }\end{array}$ & Half-life & $\begin{array}{l}\text { Decay mode } \\
(\%)\end{array}$ & $\mathrm{E}_{\gamma}(\mathrm{keV})$ & $\mathrm{I}_{\gamma}(\%)$ & Contributing reactions & Q-value $(\mathrm{MeV})$ \\
\hline \multirow[t]{2}{*}{${ }^{111 \mathrm{~m}} \mathrm{Cd}$} & $48.54 \mathrm{~min}$ & IT (100) & 245.395 & $94(7)$ & ${ }^{108} \operatorname{Pd}(\alpha, \mathrm{n})$ & -5.9 \\
\hline & & & & & ${ }^{110} \operatorname{Pd}(\alpha, 3 n)$ & -20.9 \\
\hline \multirow[t]{4}{*}{${ }^{109} \mathrm{Cd}$} & $461.4 \mathrm{~d}$ & $\varepsilon(100)$ & 88.0336 & $3.644(16)$ & ${ }^{105} \operatorname{Pd}(\alpha, \gamma)$ & 2.5 \\
\hline & & & & & ${ }^{106} \operatorname{Pd}(\alpha, n)$ & -7.0 \\
\hline & & & & & ${ }^{108} \operatorname{Pd}(\alpha, 3 n)$ & -22.8 \\
\hline & & & & & ${ }^{110} \operatorname{Pd}(\alpha, 5 n)$ & -37.8 \\
\hline \multirow[t]{3}{*}{${ }^{107} \mathrm{Cd}$} & $6.50 \mathrm{~h}$ & $\varepsilon(100)$ & 93.124 & $4.7(3)$ & ${ }^{104} \mathrm{Pd}(\alpha, \mathrm{n})$ & -8.1 \\
\hline & & & & & ${ }^{105} \operatorname{Pd}(\alpha, 2 \mathrm{n})$ & -15.1 \\
\hline & & & & & ${ }^{106} \operatorname{Pd}(\alpha, 3 \mathrm{n})$ & -24.7 \\
\hline
\end{tabular}




\begin{tabular}{|c|c|c|c|c|c|c|}
\hline & & & & & ${ }^{108} \operatorname{Pd}(\alpha, 5 n)$ & -40.5 \\
\hline \multirow[t]{4}{*}{${ }^{105} \mathrm{Cd}$} & $55.5 \mathrm{~min}$ & $\varepsilon(100)$ & 961.84 & $4.7(3)$ & ${ }^{102} \operatorname{Pd}(\alpha, n)$ & -9.2 \\
\hline & & & 346.87 & $4.2(3)$ & ${ }^{104} \operatorname{Pd}(\alpha, 3 n)$ & -26.9 \\
\hline & & & & & ${ }^{105} \mathrm{Pd}(\alpha, 4 \mathrm{n})$ & -33.9 \\
\hline & & & & & ${ }^{106} \operatorname{Pd}(\alpha, 5 n)$ & -43.5 \\
\hline \multirow[t]{3}{*}{${ }^{104} \mathrm{Cd}$} & $57.7 \mathrm{~min}$ & $\varepsilon(100)$ & 709.3 & $19.5(24)$ & ${ }^{102} \mathrm{Pd}(\alpha, 2 \mathrm{n})$ & -17.7 \\
\hline & & & & & ${ }^{104} \mathrm{Pd}(\alpha, 4 \mathrm{n})$ & -35.3 \\
\hline & & & & & ${ }^{105} \mathrm{Pd}(\alpha, 5 \mathrm{n})$ & -42.4 \\
\hline \multirow[t]{4}{*}{${ }^{111 \mathrm{~g}} \mathrm{Ag}$} & $7.45 \mathrm{~d}$ & $\beta^{-}(100)$ & 342.13 & 6.7 & ${ }^{108} \operatorname{Pd}(\alpha, p)$ & -6.2 \\
\hline & & & & & ${ }^{110} \mathrm{Pd}(\alpha, \mathrm{t})$ & -12.6 \\
\hline & & & & & ${ }^{110} \mathrm{Pd}(\alpha, \alpha \mathrm{n}){ }^{111} \mathrm{Pd}\left(\beta^{-}\right)$ & -8.8 \\
\hline & & & & & decay & \\
\hline \multirow[t]{2}{*}{${ }^{110 \mathrm{~m}} \mathrm{Ag}$} & $249.83 \mathrm{~d}$ & $\beta^{-}(98.67)$ & 657.7600 & 95.61 & ${ }^{108} \operatorname{Pd}(\alpha, d)$ & -12.8 \\
\hline & & IT (1.33) & 884.6781 & $75.0(11)$ & ${ }^{110} \operatorname{Pd}(\alpha, \operatorname{tn})$ & -21.5 \\
\hline \multirow[t]{4}{*}{$106 \mathrm{~m} A g$} & $8.28 \mathrm{~d}$ & $\varepsilon(100)$ & 450.976 & $28.2(7)$ & ${ }^{104} \operatorname{Pd}(\alpha, d)$ & -13.2 \\
\hline & & & & & ${ }^{105} \operatorname{Pd}(\alpha, \mathrm{t})$ & -14.0 \\
\hline & & & & & ${ }^{106} \operatorname{Pd}(\alpha, \operatorname{tn})$ & -23.6 \\
\hline & & & & & ${ }^{108} \operatorname{Pd}(\alpha, t 3 n)$ & -39.3 \\
\hline \multirow[t]{6}{*}{$105 \mathrm{Ag}$} & $41.29 \mathrm{~d}$ & $\varepsilon(100)$ & 344.52 & 41.4 & ${ }^{102} \operatorname{Pd}(\alpha, p)$ & -5.7 \\
\hline & & & & & ${ }^{104} \operatorname{Pd}(\alpha, t)$ & -14.8 \\
\hline & & & & & ${ }^{105} \operatorname{Pd}(\alpha, \operatorname{tn})$ & -21.9 \\
\hline & & & & & ${ }^{106} \operatorname{Pd}(\alpha, \mathrm{t} 2 \mathrm{n})$ & -31.5 \\
\hline & & & & & ${ }^{108} \operatorname{Pd}(\alpha, t 4 n)$ & -47.3 \\
\hline & & & & & ${ }^{105} \mathrm{Cd}(\varepsilon)$ decay & \\
\hline \multirow[t]{5}{*}{${ }^{103 g} \mathrm{Ag}$} & $65.7 \mathrm{~min}$ & $\varepsilon(100)$ & 118.74 & $31.2(20)$ & ${ }^{102} \operatorname{Pd}(\alpha, \mathrm{t})$ & -15.6 \\
\hline & & & & & ${ }^{104} \mathrm{Pd}(\alpha, \mathrm{t} 2 \mathrm{n})$ & -33.3 \\
\hline & & & & & ${ }^{105} \operatorname{Pd}(\alpha, \mathrm{t} 3 \mathrm{n})$ & -40.4 \\
\hline & & & & & ${ }^{106} \operatorname{Pd}(\alpha, \mathrm{t} 4 \mathrm{n})$ & -49.9 \\
\hline & & & & & ${ }^{103} \mathrm{Cd}(\varepsilon)$ decay & \\
\hline
\end{tabular}

The excitation function of the nat $\mathrm{Ti}(\alpha, \mathrm{x})^{51} \mathrm{Cr}$ monitor reaction was derived from the decay of the ${ }^{51} \mathrm{Cr}\left(\mathrm{T}_{1 / 2}=27.7025 \mathrm{~d}\right)$ isotope by measuring the activity of its $\gamma$-line at $320.0824 \mathrm{keV}\left(\mathrm{I}_{\gamma}=9.910 \%\right)$. The result is shown in Fig. 1 in comparison with the recommended value [18]. An agreement within the experimental uncertainty was found, which confirms the beam intensity measurement and the energy scale calculation throughout the stack. 


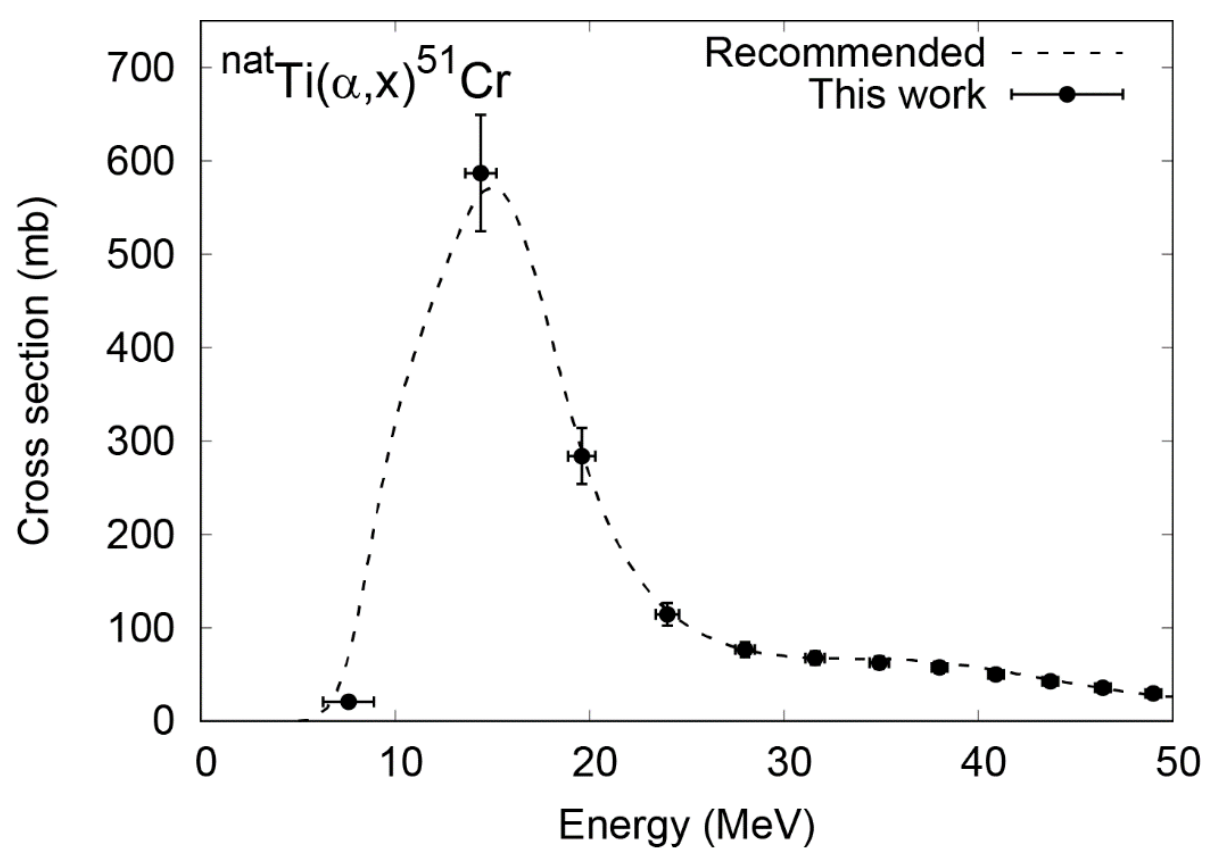

Fig. 1. Comparison of the recommended excitation function of the nat $\operatorname{Ti}(\alpha, \mathrm{x})^{51} \mathrm{Cr}$ monitor reaction with the experimental cross section values. 


\section{Result and Discussion}

The production cross sections of $\mathrm{Cd}$ and $\mathrm{Ag}$ isotopes for alpha-particle induced reactions on natPd determined in this work are summarized in Tables 2 and 3. The results graphically shown in Figs. 2-11 are compared with previous experimental data [13] and result of TALYS model calculation taken from TENDL-2017 online database [19]. The individual cross sections listed in TENDL-2017 database are multiplied by abundance of the corresponding $\mathrm{Pd}$ isotopes and summed up to be able to compare with the experimental data.

The total uncertainty was estimated to be $10.6-37.0 \%$ including statistical errors (0.1-34.8\%). It was derived from the square root of the quadratic summation of the components; the beam intensity (7\%), target thickness (2\%), target purity (1\%), detector efficiency (7\%), gamma intensity $(<7 \%)$ and peak area determination $(3 \%)$.

Table 2

Production cross sections of $\mathrm{Cd}$ isotopes.

\begin{tabular}{rrrrrr}
\hline \multicolumn{1}{l}{ Energy $(\mathrm{MeV})$} & \multicolumn{1}{l}{${ }^{111 \mathrm{~m}} \mathrm{Cd}(\mathrm{mb})$} & \multicolumn{1}{l}{${ }^{109} \mathrm{Cd}(\mathrm{mb})$} & \multicolumn{1}{l}{${ }^{107} \mathrm{Cd}(\mathrm{mb})$} & \multicolumn{1}{l}{${ }^{105} \mathrm{Cd}(\mathrm{mb})$} & ${ }^{104} \mathrm{Cd}(\mathrm{mb})$ \\
\hline $50.1 \pm 0.5$ & $21.9 \pm 2.9$ & $100.2 \pm 11.4$ & $120.0 \pm 14.8$ & $75.8 \pm 11.0$ & $20.1 \pm 3.6$ \\
$47.6 \pm 0.5$ & $28.0 \pm 3.7$ & $107.6 \pm 11.9$ & $147.6 \pm 18.3$ & $71.4 \pm 10.3$ & $13.0 \pm 2.4$ \\
$44.9 \pm 0.5$ & $38.1 \pm 4.9$ & $137.8 \pm 15.0$ & $192.4 \pm 23.8$ & $63.1 \pm 8.3$ & $6.8 \pm 1.3$ \\
$42.2 \pm 0.5$ & $67.4 \pm 8.7$ & $231.3 \pm 24.9$ & $294.2 \pm 36.4$ & $67.7 \pm 8.7$ & $3.7 \pm 0.8$ \\
$39.3 \pm 0.6$ & $98.5 \pm 12.8$ & $319.7 \pm 34.2$ & $333.3 \pm 41.2$ & $50.2 \pm 6.3$ & $2.6 \pm 0.5$ \\
$36.3 \pm 0.6$ & $135.0 \pm 17.5$ & $354.6 \pm 37.9$ & $360.0 \pm 44.5$ & $40.2 \pm 5.5$ & $4.3 \pm 0.9$ \\
$33.1 \pm 0.6$ & $138.7 \pm 18.0$ & $322.2 \pm 34.4$ & $357.6 \pm 44.2$ & $10.1 \pm 3.7$ & $6.5 \pm 1.6$ \\
$29.6 \pm 0.7$ & $101.2 \pm 13.2$ & $181.7 \pm 19.6$ & $309.9 \pm 38.3$ & & $7.8 \pm 2.2$ \\
$25.9 \pm 0.7$ & $39.7 \pm 5.3$ & $32.6 \pm 3.8$ & $296.1 \pm 36.6$ & & $7.5 \pm 2.2$ \\
$21.7 \pm 0.8$ & $20.4 \pm 2.9$ & $63.3 \pm 7.0$ & $244.3 \pm 30.2$ & & \\
$17.0 \pm 1.0$ & $44.6 \pm 6.2$ & $115.1 \pm 12.2$ & $55.9 \pm 6.9$ & & \\
$11.1 \pm 1.2$ & & & $0.25 \pm 0.03$ & &
\end{tabular}

Table 3

Production cross sections of Ag isotopes.

\begin{tabular}{rrrrrr}
\hline Energy $(\mathrm{MeV})$ & \multicolumn{1}{l}{${ }^{111 \mathrm{~g} A g}(\mathrm{mb})$} & \multicolumn{1}{l}{${ }^{110 \mathrm{~m} A g}(\mathrm{mb})$} & \multicolumn{1}{l}{${ }^{106 \mathrm{~m} A g}(\mathrm{mb})$} & \multicolumn{1}{l}{${ }^{105 \mathrm{gg}}(\mathrm{mb})$} & \multicolumn{1}{l}{${ }^{103 \mathrm{Ag}}(\mathrm{mb})$} \\
\hline $50.1 \pm 0.5$ & $14.4 \pm 1.7$ & $10.7 \pm 1.2$ & $80.3 \pm 8.7$ & $242.2 \pm 26.3$ & $6.5 \pm 0.9$ \\
$47.6 \pm 0.5$ & $15.4 \pm 1.8$ & $9.4 \pm 1.0$ & $74.8 \pm 8.1$ & $220.3 \pm 23.9$ & $7.6 \pm 1.0$ \\
$44.9 \pm 0.5$ & $14.2 \pm 1.6$ & $8.1 \pm 0.9$ & $68.1 \pm 7.4$ & $190.4 \pm 20.7$ & $8.1 \pm 1.0$ \\
$42.2 \pm 0.5$ & $16.8 \pm 2.0$ & $9.1 \pm 1.0$ & $76.3 \pm 8.3$ & $186.1 \pm 20.2$ & $9.2 \pm 1.2$
\end{tabular}




$\begin{array}{lrrrrr}39.3 \pm 0.6 & 14.3 \pm 1.7 & 9.3 \pm 1.0 & 65.6 \pm 7.1 & 142.0 \pm 15.4 & 7.6 \pm 0.9 \\ 36.3 \pm 0.6 & 10.9 \pm 1.2 & 10.0 \pm 1.1 & 52.2 \pm 5.7 & 98.8 \pm 10.7 & 4.7 \pm 0.6 \\ 33.1 \pm 0.6 & 7.6 \pm 0.9 & 10.4 \pm 1.1 & 35.6 \pm 3.9 & 42.7 \pm 4.6 & 1.1 \pm 0.4 \\ 29.6 \pm 0.7 & 5.5 \pm 0.7 & 7.0 \pm 0.8 & 19.0 \pm 2.1 & 5.1 \pm 0.6 & \\ 25.9 \pm 0.7 & 5.0 \pm 0.6 & 2.8 \pm 0.3 & 8.1 \pm 0.9 & 3.8 \pm 0.4 \\ 21.7 \pm 0.8 & 3.3 \pm 0.4 & 0.22 \pm 0.04 & 0.54 \pm 0.06 & 9.0 \pm 1.0 \\ 17.0 \pm 1.0 & 0.33 \pm 0.04 & & & 4.7 \pm 0.5 & \\ 11.1 \pm 1.2 & 0.018 \pm 0.005 & & & 0.068 \pm 0.012 & \end{array}$




\subsection{The ${ }^{\text {nat } P d}(\alpha, x){ }^{111 m}$ Cd Reaction}

The excitation function of the nat $P d(\alpha, x) 111 \mathrm{mCd}$ reaction was derived from the measurement of the $\gamma$-line at $245.395 \mathrm{keV}\left(\mathrm{I}_{\gamma}=94 \%\right)$. The result is shown in Fig. 2 together with previous experimental data and TENDL-2017 data. The excitation function of this reaction has two wide peaks at around 15 and $35 \mathrm{MeV}$, corresponding to contributions of two stable isotopes of palladium, ${ }^{108} \mathrm{Pd}$ and ${ }^{110} \mathrm{Pd}$. Our data are in general agreement with the earlier published data. However, the amplitude of our result is slightly larger than both the data published before as well as the result of TALYS calculation at around the peak at $35 \mathrm{MeV}$.

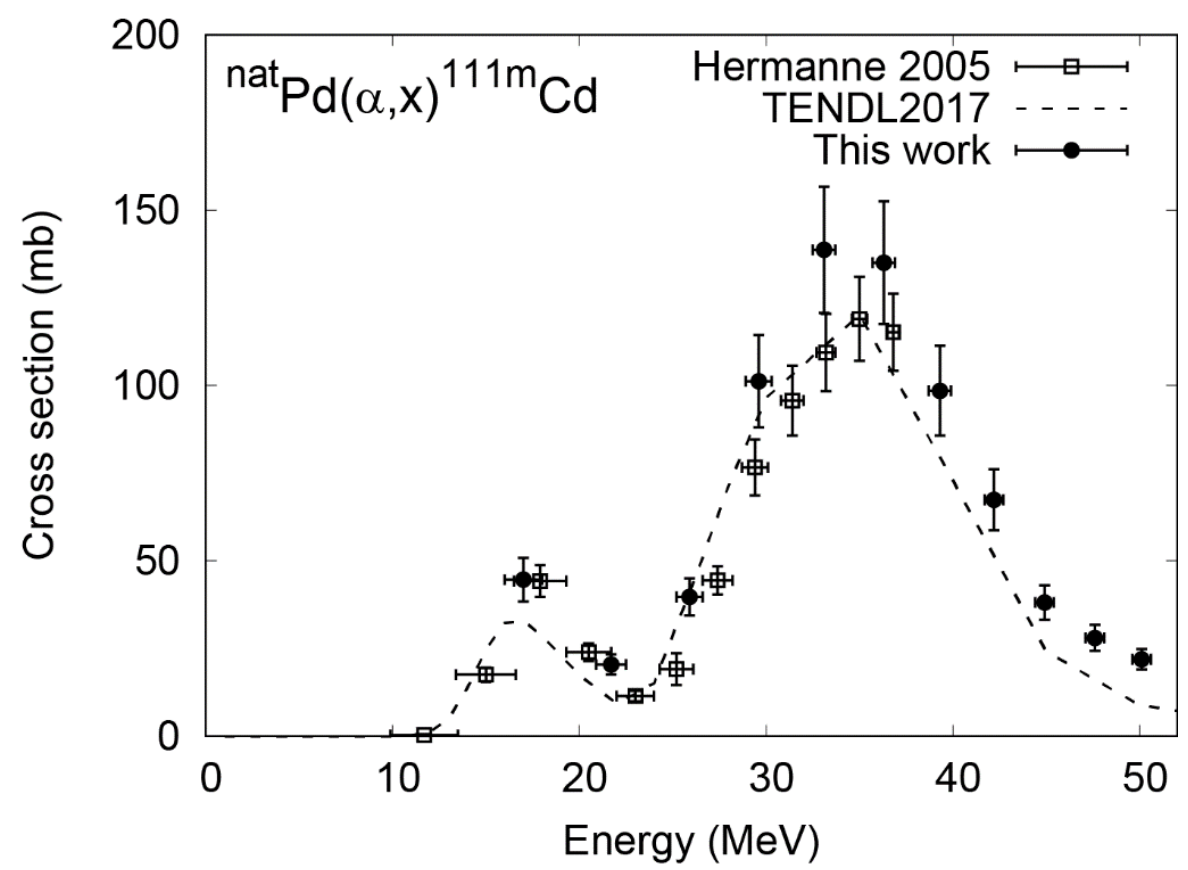

Fig. 2. The excitation function of the nat $\mathrm{Pd}(\alpha, \mathrm{x})^{111 \mathrm{~m}} \mathrm{Cd}$ reaction. 


\subsection{The ${ }^{\text {nat } P d}(\alpha, x){ }^{109} \mathrm{Cd}$ Reaction}

The $\gamma$-line at $88.0336 \mathrm{keV}\left(\mathrm{I}_{\gamma}=3.644 \%\right)$ from the decay of ${ }^{109} \mathrm{Cd}\left(\mathrm{T}_{1 / 2}=461.4 \mathrm{~d}\right)$ was measured after a long cooling time (244 days) to reduce the effect of other coproduced radioisotopes. The excitation function of the nat $\mathrm{Pd}(\alpha, \mathrm{x}){ }^{109} \mathrm{Cd}$ reaction is shown in Fig. 3 in comparison with TENDL-2017 data. The result has two peaks at around 15 and 35 $\mathrm{MeV}$, corresponding to the dominant contribution of the reactions on the ${ }^{106} \mathrm{Pd}$ and ${ }^{108} \mathrm{Pd}$ target isotopes. It has a similar shape with but different amplitudes from that of the ${ }_{\text {nat }} \operatorname{Pd}(\alpha, \mathrm{x}){ }^{111 \mathrm{~m} C d}$ reaction. No earlier experimental data are available for this reaction. Our result shows slightly larger values, however the behavior is consistent with data of TENDL-2017 database.

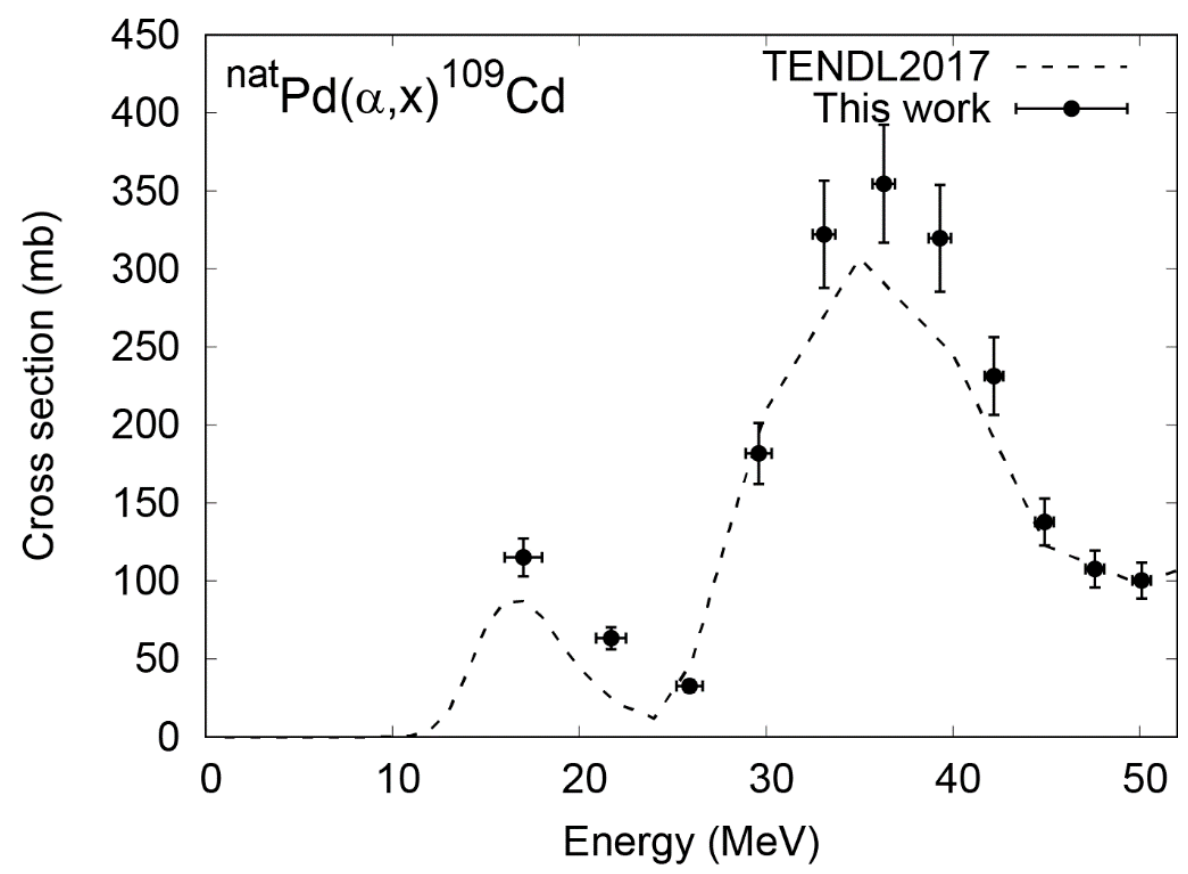

Fig. 3. The excitation function of the ${ }^{\text {nat }} \mathrm{Pd}(\alpha, \mathrm{x})^{109} \mathrm{Cd}$ reaction. 


\subsection{The ${ }^{\text {nat } P d}(\alpha, x){ }^{107} \mathrm{Cd}$ Reaction}

The production cross sections of ${ }^{107} \mathrm{Cd}\left(\mathrm{T}_{1 / 2}=6.50 \mathrm{~h}\right)$ were measured using the independent $\gamma$-line at $93.124 \mathrm{keV}\left(\mathrm{I}_{\gamma}=4.7 \%\right)$. The result is shown in Fig. 4 together with data from TENDL-2017 database. There are three contributing reactions, the ${ }^{104} \operatorname{Pd}(\alpha, n)$, ${ }^{105} \mathrm{Pd}(\alpha, 2 \mathrm{n})$ and ${ }^{106} \mathrm{Pd}(\alpha, 3 \mathrm{n})$ reactions, which compose one broad peak at around $35 \mathrm{MeV}$. The shape is different from those of the nat $\mathrm{Pd}(\alpha, \mathrm{x}) 109,111 \mathrm{mCd}$ reactions having two independent peaks dominated by two contributing reactions. The result of TALYS calculation represents relatively well our experimental data.

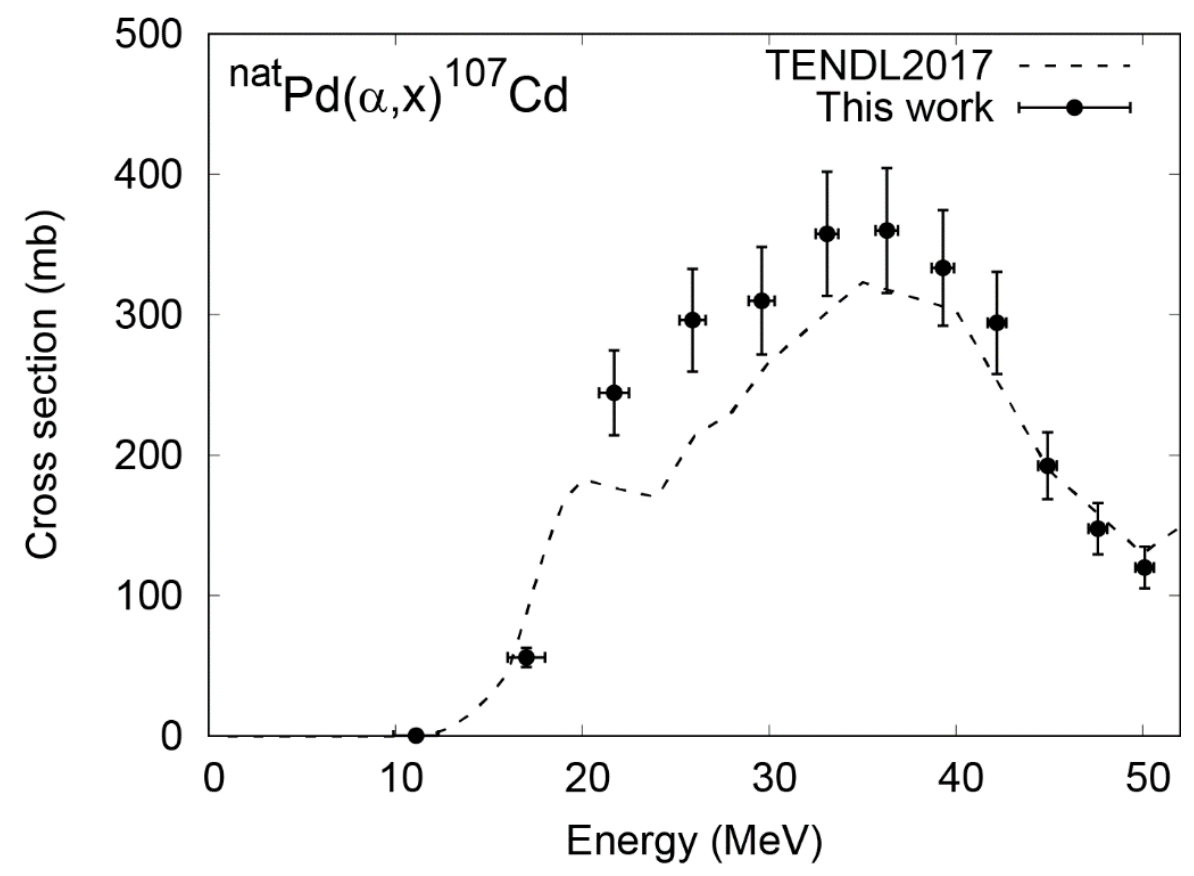

Fig. 4. The excitation function of the ${ }^{\text {nat }} \mathrm{Pd}(\alpha, \mathrm{x}){ }^{107} \mathrm{Cd}$ reaction. 


\subsection{The ${ }^{\text {nat } P d}(\alpha, x){ }^{105} \mathrm{Cd}$ Reaction}

The $\gamma$-line at $961.84 \mathrm{keV}\left(\mathrm{I}_{\gamma}=4.7 \%\right)$ from the decay of ${ }^{105} \mathrm{Cd}\left(\mathrm{T}_{1 / 2}=55.4 \mathrm{~min}\right)$ was assessed for determining the excitation function of the ${ }^{n a t} \mathrm{Pd}(\alpha, \mathrm{x}){ }^{105} \mathrm{Cd}$ process. This $\gamma^{-}$ line has a negligible interference with the $962.43 \mathrm{keV} \gamma$-line $\left(\mathrm{I}_{\gamma}=0.124 \%\right)$ from the decay of much longer-lived ${ }^{105} \mathrm{Ag}$ coproduced isotope $\left(\mathrm{T}_{1 / 2}=41.29 \mathrm{~d}\right)$. The measurement was performed after a cooling time of 3.6 hours. The derived result is shown in Fig. 5 in comparison with earlier experimental data and result of theoretical estimation taken from TENDL-2017 database. The earlier data are slightly higher than our data and the theoretical calculation is overestimate both of the experimental data sets above $30 \mathrm{MeV}$.

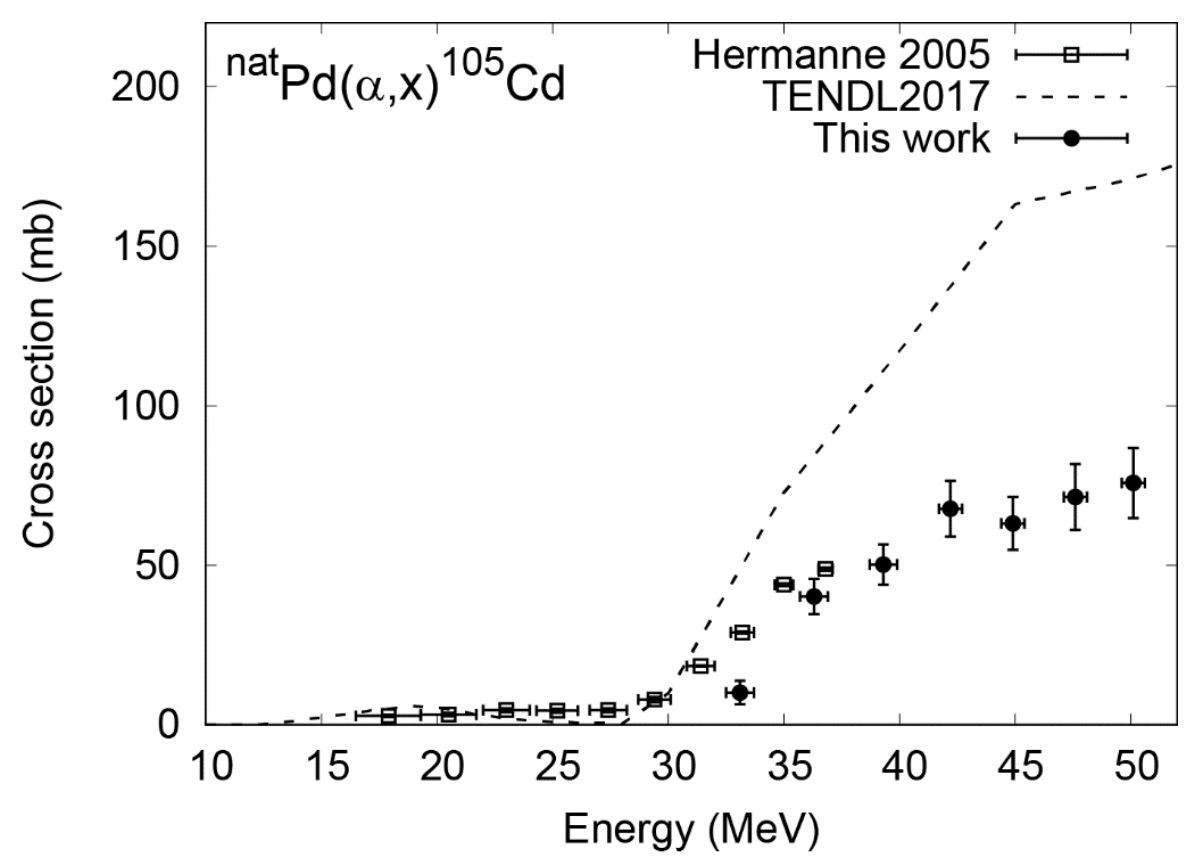

Fig. 5. The excitation function of the nat $\mathrm{Pd}(\alpha, \mathrm{x})^{105} \mathrm{Cd}$ reaction. 


\subsection{The ${ }^{\text {nat } P d}(\alpha, x){ }^{104} \mathrm{Cd}$ Reaction}

The $\gamma$-line at $709.3 \mathrm{keV}\left(\mathrm{I}_{\gamma}=19.5 \%\right)$ from the decay of ${ }^{104} \mathrm{Cd}\left(\mathrm{T}_{1 / 2}=57.7 \mathrm{~min}\right)$ was used for determination the excitation function of the nat $\mathrm{Pd}(\alpha, \mathrm{x}){ }^{104} \mathrm{Cd}$ reaction. There are small overlapped contributions to the total peak area from decay of ${ }^{105} \mathrm{Cd}$ and ${ }^{111} \mathrm{Pd}$. The contribution of $709.87 \mathrm{keV} \gamma$-line $\left(\mathrm{I}_{\gamma}=0.127 \%\right)$ from the ${ }^{105} \mathrm{Cd}$ decay was subtracted using the cross sections obtained in section 3.4. The $709.8 \mathrm{keV} \gamma$-line $\left(\mathrm{I}_{\gamma}=0.131 \%\right)$ from the ${ }^{111} \mathrm{Pd}$ decay was negligible because the $\gamma$-line at $172.18 \mathrm{keV}\left(\mathrm{I}_{\gamma}=46 \%\right)$ could not be found. The more intense $\gamma$-line at $83.5 \mathrm{keV}\left(\mathrm{I}_{\gamma}=47 \%\right)$ has a strong contribution from decay of ${ }^{100} \mathrm{Pd}$ and therefore unselected. The result is shown in Fig. 6 with earlier experimental data and data from TENDL-2017 data library. The previous data are in good agreement with our data. The theoretical estimation also gives relatively not too bad description of the experimental data of this process.

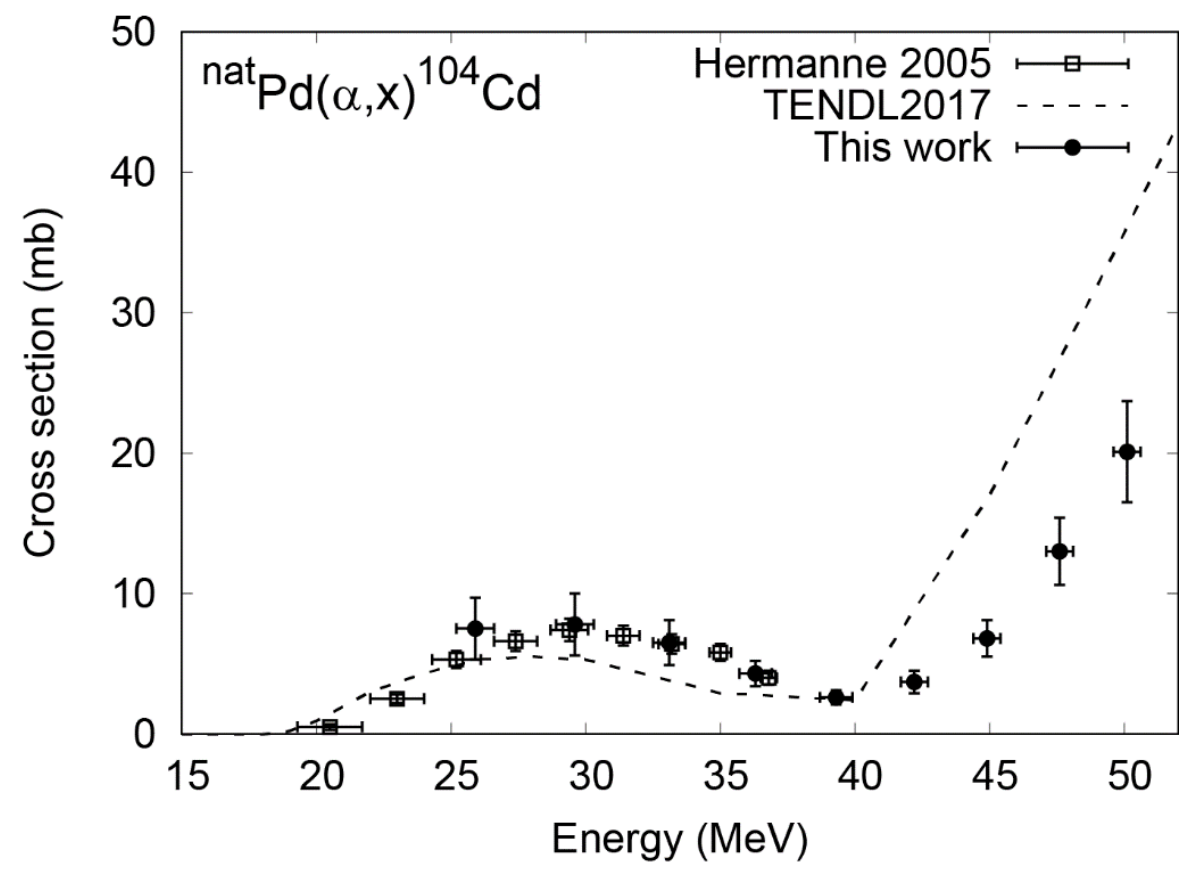

Fig. 6. The excitation function of the ${ }^{\text {nat }} \mathrm{Pd}(\alpha, \mathrm{x}){ }^{104} \mathrm{Cd}$ reaction. 


\subsection{The natPd $(\alpha, x)^{111 g A g}$ Reaction}

${ }^{111} \mathrm{Ag}$ has an excited isomeric state ${ }^{111 \mathrm{~m} A g}\left(\mathrm{~T}_{1 / 2}=64.8 \mathrm{~s}\right)$ decaying almost completely to the ground state ${ }^{111 \mathrm{~g} A g}\left(\mathrm{~T}_{1 / 2}=7.45 \mathrm{~d}\right)$ and contributes its population. Both isomeric states of ${ }^{111} \mathrm{Pd}$, the ${ }^{111 \mathrm{gPd}}\left(\mathrm{T}_{1 / 2}=23.4 \mathrm{~min}\right)$ and ${ }^{111 \mathrm{mPd}}\left(\mathrm{T}_{1 / 2}=5.5 \mathrm{~h}\right)$, were produced in the ${ }^{n a t} \mathrm{Pd}(\alpha, \mathrm{x}){ }^{111} \mathrm{Pd}$ process and contributed to the ${ }^{111 \mathrm{~g}} \mathrm{Ag}$ production. The ${ }^{\mathrm{nat}} \mathrm{Pd}(\alpha, \mathrm{x}){ }^{111 \mathrm{~g}} \mathrm{Ag}$ reaction is thus cumulative one. The interference free $\gamma$-line at $342.13 \mathrm{keV}\left(\mathrm{I}_{\gamma}=6.7 \%\right)$ from the decay of ${ }^{111 \mathrm{~g} A g}$ has been measured after the cooling time of about 60 hours. The result is shown in Fig. 7 together with earlier published experimental data and prediction of TALYS calculation. Our results are in good agreement with previous experimental data. The theoretical calculation underestimates the experimental values, but provides an excitation function with a similar shape.

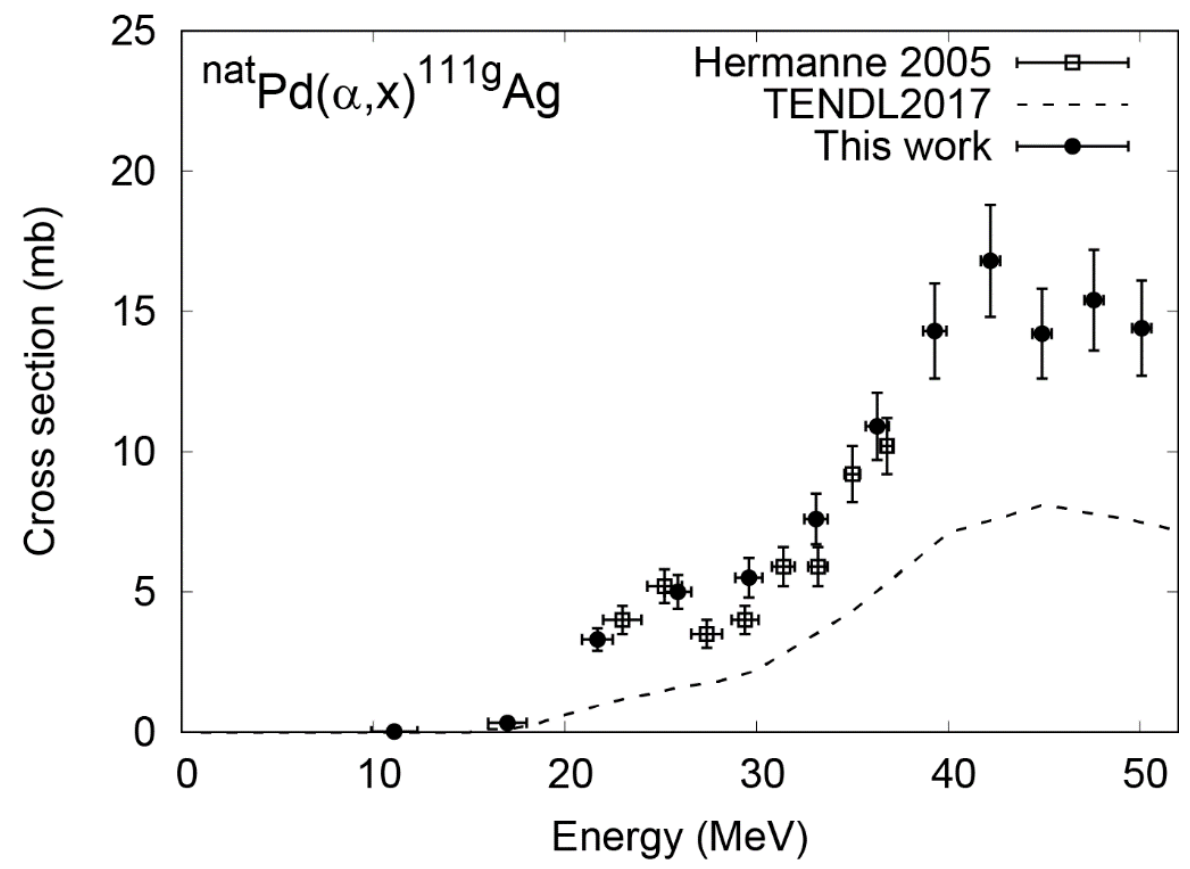

Fig. 7. The excitation function of the ${ }^{\text {nat }} \mathrm{Pd}(\alpha, \mathrm{x})^{111 \mathrm{~g}} \mathrm{Ag}$ reaction. 


\subsection{The ${ }^{\text {natPd}}(\alpha, x) 110 \mathrm{~m} A g$ Reaction}

The ${ }^{110} \mathrm{Ag}$ isotope has a short-lived ground state $\left(\mathrm{T}_{1 / 2}=24.5 \mathrm{~s}\right)$ and a much longer-lived excited isomeric state ${ }^{110 \mathrm{~m}} \mathrm{Ag}\left(\mathrm{T}_{1 / 2}=249.83 \mathrm{~d}\right)$. The interference free $\gamma$-line at $657.7600 \mathrm{keV}\left(\mathrm{I}_{\gamma}=\right.$ 95.61\%) from the decay of $110 \mathrm{~m} \mathrm{Ag}$ has been used for determining the excitation function of the ${ }^{n a t} \mathrm{Pd}(\alpha, \mathrm{x}){ }^{110 \mathrm{~m}} \mathrm{Ag}$ reaction. The measurement was performed after a long cooling time of 244 days. Our results are shown in Fig. 8 together with the experimental data published earlier and results of theoretical calculation taken from TENDL-2017 database. The earlier measured data are in agreement with our result up to $30 \mathrm{MeV}$, but systematically higher above that energy. The theoretical calculation significantly underestimates this process.

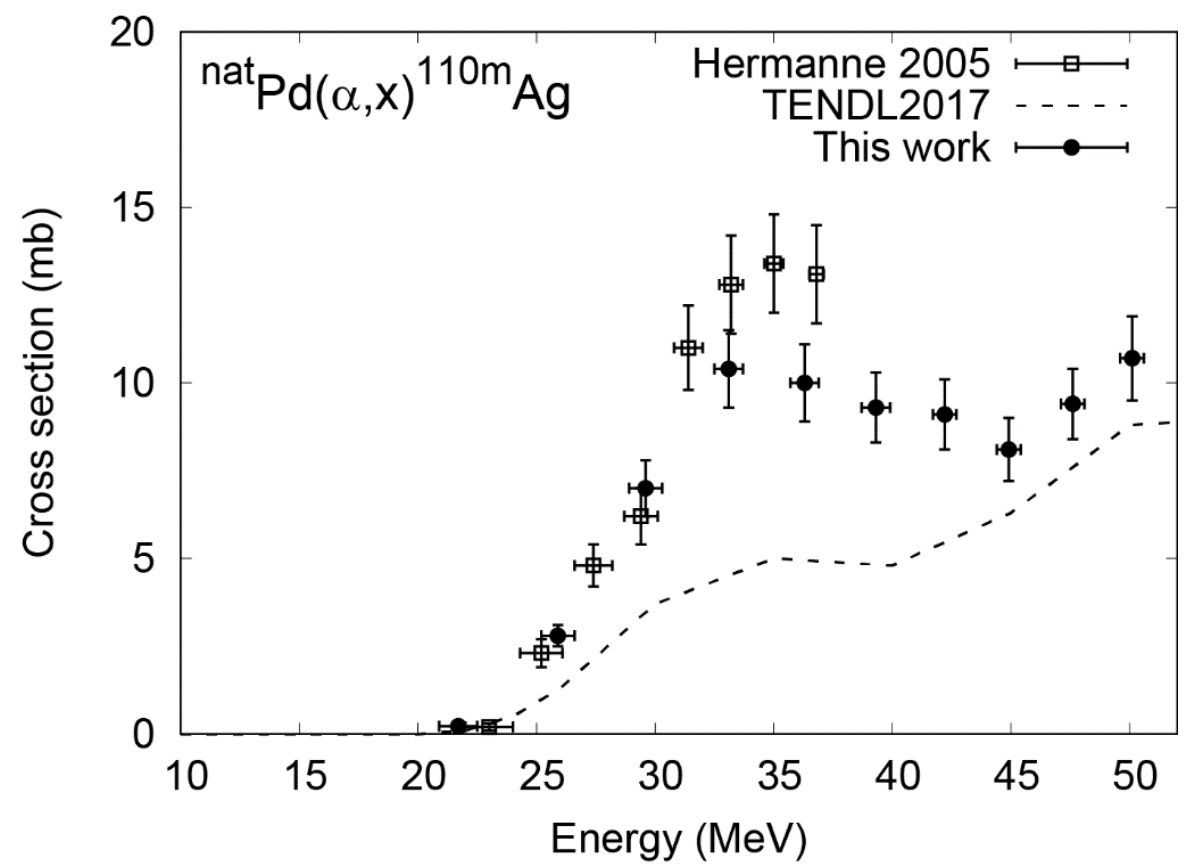

Fig. 8. The excitation function of the nat $\mathrm{Pd}(\alpha, \mathrm{x})^{110 \mathrm{~m}} \mathrm{Ag}$ reaction. 


\subsection{The ${ }^{\text {nat } P d}(\alpha, x){ }^{106 m} \mathrm{Ag}$ Reaction}

The ${ }^{106} \mathrm{Ag}$ isotope has a short-lived ground state ${ }^{106 \mathrm{~g}} \mathrm{Ag}\left(\mathrm{T}_{1 / 2}=23.96 \mathrm{~min}\right)$ and a longerlived isomeric state $106 \mathrm{~m} A g\left(\mathrm{~T}_{1 / 2}=8.28 \mathrm{~d}\right)$. In this work only the higher energy isomeric state was assessed. The $\gamma$-line at $450.976 \mathrm{keV}\left(\mathrm{I}_{\gamma}=28.2 \%\right)$ from the decay of $106 \mathrm{~m} \mathrm{Ag}$ has been used to determine the cross section for this process after cooling time about 55 hours. This $\gamma$-line can be considered as independent after the applied cooling time when ${ }^{106 \mathrm{~m} R \mathrm{~h}}$ $\left(\mathrm{T}_{1 / 2}=131 \mathrm{~min}\right)$ had completely decayed. The result is shown in Fig. 9 in comparison with the earlier experimental data and data taken from TENDL-2017 data library. The two experimental datasets are in good agreement with each other and the theoretical calculation also describes relatively well the experimental excitation function.

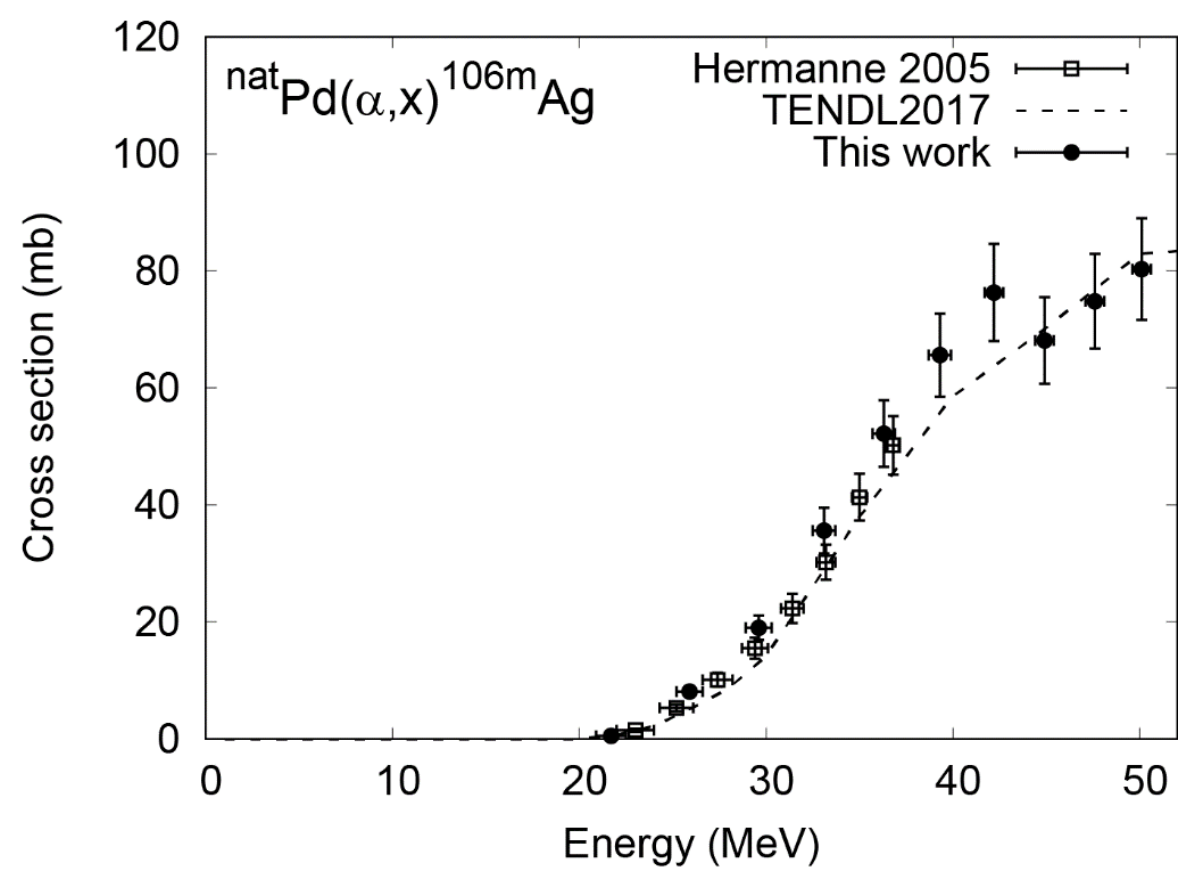

Fig. 9: The excitation function of the nat $\mathrm{Pd}(\alpha, \mathrm{x}){ }^{106 \mathrm{~m}} \mathrm{Ag}$ reaction. 


\subsection{The natPd $(\alpha, x)^{105 g A g}$ Reaction}

The excitation function provided for the ${ }^{n a t} \operatorname{Pd}(\alpha, x){ }^{105 g} \mathrm{Ag}$ reaction is cumulative since the decay of ${ }^{105 \mathrm{~m} A g}\left(\mathrm{~T}_{1 / 2}=7.23 \mathrm{~min}\right)$ and ${ }^{105} \mathrm{Cd}\left(\mathrm{T}_{1 / 2}=55.5 \mathrm{~min}\right)$ contribute to the formation of ${ }^{105 \mathrm{~g} A g}$. The $\gamma$-line at $344.52 \mathrm{keV}\left(\mathrm{I}_{\gamma}=41.4 \%\right)$ from the decay of $105 \mathrm{gAg}\left(\mathrm{T}_{1 / 2}=\right.$ $41.29 \mathrm{~d}$ ) has been measured and is free from interferences after the long cooling time of about 60 days. The result is shown in Fig. 10 together with experimental data published earlier and result of TALYS model calculation taken from TENDL-2017 data library. Our result is in good agreement with the previous data and theoretical estimation also describes well this process, although the theoretical calculation overestimates the ${ }^{n a t} \mathrm{Pd}(\alpha, \mathrm{x}){ }^{105} \mathrm{Cd}$ reaction which contributes to this process.

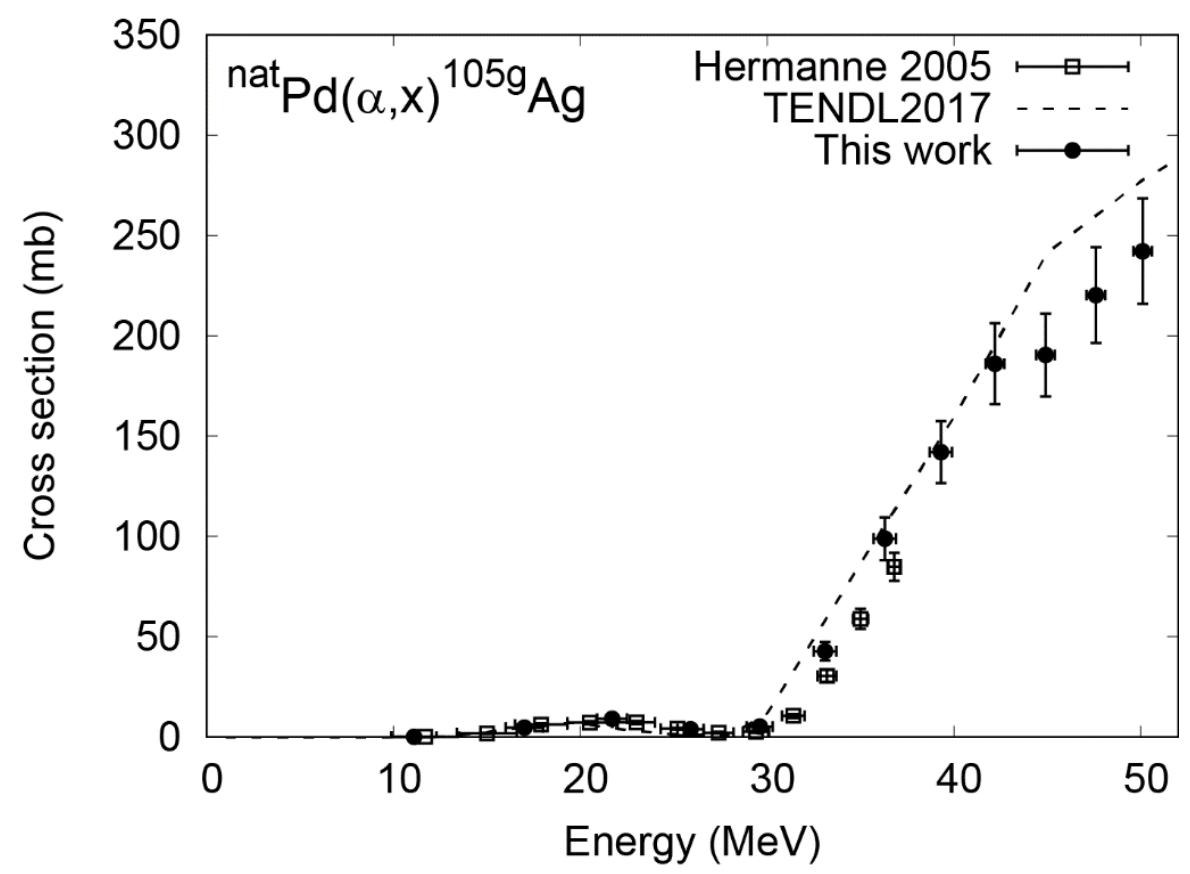

Fig. 10. The excitation function of the natPd(a,x $)^{105 g} \mathrm{Ag}$ reaction. 


\subsection{The natPd $(\alpha, x){ }^{103 g A g}$ Reaction}

The $\gamma$-line at $118.74 \mathrm{keV}\left(\mathrm{I}_{\gamma}=31.2 \%\right)$ from the decay of $103 \mathrm{~g} \mathrm{Ag}\left(\mathrm{T}_{1 / 2}=65.7 \mathrm{~min}\right)$ was measured after a cooling time of 3.6 hours and used to determine the excitation function of this process. Beside the direct production, ${ }^{103 \mathrm{~g}} \mathrm{Ag}$ is populated by decay of its higher energy isomer state and by decay of ${ }^{103} \mathrm{Cd}\left(\mathrm{T}_{1 / 2}=7.3 \mathrm{~min}\right)$, and therefore cumulative cross sections are deduced. There are minor contributions to this peak area from coproduced isotopes, but their total contribution is negligibly small. The result is shown in Fig. 11 in comparison with earlier experimental data and data from TENDL-2017 library. Our result is slightly higher than the previous experimental data. The TALYS calculation provides an excitation function with a consistent tendency.

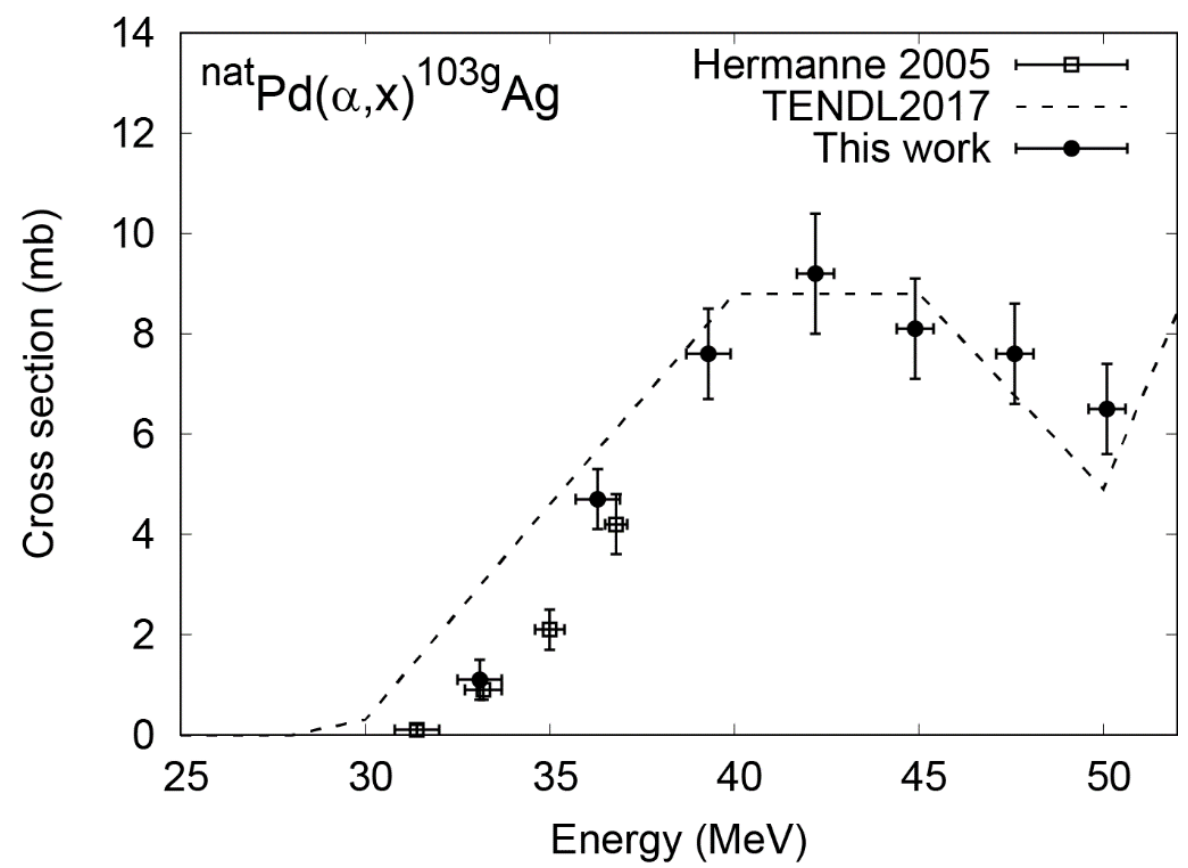

Fig. 11. The excitation function of the nat $\mathrm{Pd}(\alpha, \mathrm{x})^{103 \mathrm{~g}} \mathrm{Ag}$ reaction. 


\section{Conclusion}

We have studied the alpha-particle induced nuclear reactions of palladium and

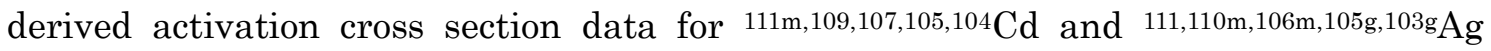
isotopes. The newly measured experimental cross sections were compared to the available earlier published data and in most cases agreement was found. The prediction of TALYS theoretical model calculation was also compared to the experimental data and acceptable agreement was found. The new data at the higher energy region up to $50 \mathrm{MeV}$ enrich nuclear reaction databases and are available for improvement of theoretical model calculations.

\section{Acknowledgement}

The experiment was carried out at RI Beam Factory operated by RIKEN Nishina Center and CNS, University of Tokyo, Japan. This work is supported by the Japan Hungary Research Cooperative Program, JSPS and HAS and by JSPS KAKENHI Grant Number 17K07004.

\section{Reference}

[1] F. Ditrói, F. Tárkányi, S. Takács, A. Hermanne, New developments in the experimental data for charged particle production of medical radioisotopes, J. Radioanal. Nucl. Chem. 305 (2015) 247-253. doi:10.1007/s10967-015-3968-x.

[2] S.M. Qaim, Nuclear data for production and medical application of radionuclides: Present status and future needs, Nucl. Med. Biol. 44 (2017) 31-49. doi:10.1016/j.nucmedbio.2016.08.016.

[3] S. Nag, D. Beyer, J. Friedland, P. Grimm, R. Nath, American brachytherapy society (ABS) recommendations for transperineal permanent brachytherapy of prostate cancer, Int. J. Radiat. Oncol. Biol. Phys. 44 (1999) 789-799. doi:10.1016/S03603016(99)00069-3.

[4] A. Hermanne, S. Takács, F. Tárkányi, R. Bolbos, Cross section measurements of proton and deuteron induced formation of ${ }^{103} \mathrm{Ag}$ in natural palladium, Radiochim. Acta. 92 (2004) 215-218. doi:10.1524/ract.92.4.215.35609.

[5] Z. Szucs, J. van Rooyen, J.R. Zeevaart, Recoil effect on B-decaying in vivo generators, interpreted for ${ }^{103} \mathrm{Pd} / 103 \mathrm{~m} R \mathrm{Rh}$, Appl. Radiat. Isot. 67 (2009) 1401-1404. doi:10.1016/j.apradiso.2009.02.022.

[6] N. Otuka, E. Dupont, V. Semkova, B. Pritychenko, A.I. Blokhin, M. Aikawa, S. 
Babykina, M. Bossant, G. Chen, S. Dunaeva, R.A. Forrest, T. Fukahori, N. Furutachi, S. Ganesan, Z. Ge, O.O. Gritzay, M. Herman, S. Hlavač, K. Kato, B. Lalremruata, Y.O. Lee, A. Makinaga, K. Matsumoto, M. Mikhaylyukova, G. Pikulina, V.G. Pronyaev, A. Saxena, O. Schwerer, S.P. Simakov, N. Soppera, R. Suzuki, S. Takács, X. Tao, S. Taova, F. Tárkányi, V. V. Varlamov, J. Wang, S.C. Yang, V. Zerkin, Y. Zhuang, Towards a More complete and accurate experimental nuclear reaction data library (EXFOR): International collaboration between nuclear reaction data centres (NRDC), Nucl. Data Sheets. 120 (2014) 272-276. doi:10.1016/j.nds.2014.07.065.

[7] F. Tárkányi, A. Hermanne, B. Király, S. Takács, F. Ditrói, J. Csikai, A. Fenyvesi, M.S. Uddin, M. Hagiwara, M. Baba, T. Ido, Y.N. Shubin, A. V. Ignatyuk, New crosssections for production of ${ }^{103} \mathrm{Pd}$; review of charged particle production routes, Appl. Radiat. Isot. 67 (2009) 1574-1581. doi:10.1016/j.apradiso.2009.03.100.

[8] M.U. Khandaker, K. Kim, G. Kim, Production cross sections of short-lived silver radionuclides from ${ }^{\text {nat }} \mathrm{Pd}(\mathrm{p}, \mathrm{xn})$ nuclear processes, Nucl. Instruments Methods Phys. Res. Sect. B. 274 (2012) 148-153. doi:10.1016/j.nimb.2011.12.022.

[9] F. Tárkányi, F. Ditrói, S. Takács, J. Csikai, A. Hermanne, M.S. Uddin, M. Baba, Activation cross sections of proton induced nuclear reactions on palladium up to 80 MeV, Appl. Radiat. Isot. 114 (2016) 128-144. doi:10.1016/j.apradiso.2016.05.022.

[10] F. Ditrói, F. Tárkányi, S. Takács, A. Hermanne, A. V. Ignatyuk, Measurement of activation cross-section of long-lived products in deuteron induced nuclear reactions on palladium in the 30-50 MeV energy range, Appl. Radiat. Isot. 128 (2017) 297-306. doi:10.1016/j.apradiso.2017.07.049.

[11] N. Ukon, M. Aikawa, Y. Komori, H. Haba, Production cross sections of deuteroninduced reactions on natural palladium for Ag isotopes, Nucl. Instruments Methods Phys. Res. Sect. B. 426 (2018) 13-17. doi:10.1016/j.nimb.2018.04.019.

[12] M. Al-Abyad, F. Tárkányi, F. Ditrói, S. Takács, Excitation function of ${ }^{3} \mathrm{He}$-particle induced nuclear reactions on natural palladium, Appl. Radiat. Isot. 94 (2014) 191199. doi:10.1016/j.apradiso.2014.08.002.

[13] A. Hermanne, F. Tárkányi, S. Takács, Y.N. Shubin, Experimental determination of cross section of alpha-induced reactions on natPd, Nucl. Instruments Methods Phys. Res. Sect. B. 229 (2005) 321-332. doi:10.1063/1.1945164.

[14] T. Watanabe, M. Fujimaki, N. Fukunishi, H. Imao, O. Kamigaito, M. Kase, M. Komiyama, N. Sakamoto, K. Suda, M. Wakasugi, K. Yamada, BEAM ENERGY AND LONGITUDINAL BEAM PROFILE MEASUREMENT SYSTEM AT THE RIBF, in: Proc. 5th Int. Part. Accel. Conf. (IPAC 2014), 2014: pp. 3566-3568. 
[15] J.F. Ziegler, J.P. Biersack, M.D. Ziegler, SRIM: the Stopping and Range of Ions in Matter, (2008). doi:10.1016/j.nimb.2004.01.208.4.

[16] National Nuclear Data Center, Nuclear structure and decay data on-line library, Nudat 2.7, (2017). http://www.nndc.bnl.gov/nudat2/.

[17] B. Pritychenko, A. Sonzogni, Q-value Calculator (QCalc), (2003). http://www.nndc.bnl.gov/qcalc/.

[18] F. Tárkányi, S. Takács, K. Gul, A. Hermanne, M.G. Mustafa, M. Nortier, P. Obložinský, S.M. Qaim, B. Scholten, Y.N. Shubin, Z. Yousiang, Beam monitor reactions, in: Charg. Part. Cross-Section Database Med. Radioisot. Prod. IAEATECDOC-1211, 2001. https://www-nds.iaea.org/medical/monitor_reactions.html.

[19] A.J. Koning, D. Rochman, Modern Nuclear Data Evaluation with the TALYS Code System, Nucl. Data Sheets. 113 (2012) 2841-2934. doi:10.1016/j.nds.2012.11.002. 